\title{
Heating effects in WC-Co cemented carbides as a result of reciprocative dry sliding friction
}

\author{
K. Bonny ${ }^{1, a}$, P. De Baets ${ }^{1, b}$, O. Van der Biest ${ }^{2, c}$, J. Vleugels ${ }^{2, d}$, B. Lauwers ${ }^{3, e}$ \\ ${ }^{1}$ Ghent University (UGent), Dep. Mechanical Construction \& Production, IR04, Belgium \\ ${ }^{2}$ Catholic University Leuven (K.U.Leuven), Dep. Metallurgy \& Materials Engineering, MTM, Belgium \\ ${ }^{3}$ Catholic University Leuven (K.U.Leuven), Dep. Mechanical Engineering, PMA, Belgium \\ akoenraad.bonny@ugent.be, ${ }^{b}$ patrick.debaets@ugent.be, comer.vanderbiest@mtm.kuleuven.be, \\ djozef.vleugels@mtm.kuleuven.be, 'bert.lauwers@mech.kuleuven.be
}

Keywords: cemented carbide, dry reciprocating sliding, frictional heating, pin on plate.

\begin{abstract}
WC-Co based cemented carbides are widely used in technical applications, in which they are exposed to complex thermo-mechanical loadings. Previous research work has demonstrated that these materials exhibit a lifetime-limiting fatigue sensitivity at room temperature. This investigation is focused on the influence of heating as a result of friction of pin-on-plate tribocouples. WC-Co samples have been manufactured and surface finished by wire-EDM and grinding. Reciprocative dry friction experiments are performed under various loading conditions and sliding velocities. Correlations are established between the bulk temperature rise of the test samples and the imposed test conditions, material properties, surface conditions and coefficient of friction. Topographies and cross-section views of the tested samples were examined by SEM, revealing temperature dependent wear mechanisms, including binder phase modification.
\end{abstract}

\section{Introduction}

A growing trend in industry is $d r y$ machining, in order to reduce environmental and production costs [1,2]. WC-Co cemented carbides are extensively used as tool materials in machining and forming of metals and alloys, as they display an exceptional combination of superior wear resistance and excellent toughness. However, some of their attractive properties may deteriorate as a result of extremely high cutting temperatures induced by frictional heating, in case of machining without any cutting fluid [3].

The aim of this paper was to investigate the influence of heating as a result of dry friction between WC-Co/WC-Co cemented carbide sliding couples. Systematic pin-on-plate experiments were performed using a small-scale tribometer, at different starting temperatures and initial surface finishing conditions, applying various contact loads and oscillating speeds. At the same time, bulk temperature measurements were conducted on the WC-Co test samples. Scanning electron micrographs of the tested samples revealed the occurrence of temperature dependent wear mechanisms, including binder phase modification.

\section{Experimental}

WC-Co cemented carbides. The cemented carbide grades consist of hard WC grains, cemented in a binder matrix of tough Co by liquid phase sintering. They were manufactured by wire-EDM (ROBOFIL 2030SI, Charmilles Technologies) or grinding (JF415DS, Jung, Göppingen, Germany) with a diamond grinding wheel (type MD4075B55, Wendt Boart, Brussels, Belgium). More details about the EDM parameters and the concomitant surface roughnesses, together with the chemical, physical, mechanical and microstructural properties of the WC-Co cemented carbide are described elsewhere [4,5]. In this paper, one rough and one fine EDM cut, as well as ground surface finishes were selected for dry sliding experiments. 
Testing procedure. The impact of frictional heating as a result of dry sliding between WC-Co cemented carbides was examined using a reciprocative sliding wear test, according to an ASTM G133 pin-on-plate system. The tip of the pins was a hemisphere, with average rounding radius and roughness parameters $R_{a}$ and $R_{t}$ of $4.08 \mathrm{~mm}, 0.35 \mu \mathrm{m}$ and $2.68 \mu \mathrm{m}$ respectively. The counter plates (width $38 \mathrm{~mm}$, length $58 \mathrm{~mm}$, thickness $4 \mathrm{~mm}$ ) are fixed to a stationary specimen holder. The temperature was monitored by (i) a $\mathrm{K}$-type $\mathrm{NiCr} / \mathrm{NiAl}$ thermocouple (T1) welded at the top of the plate specimen, (ii) a temperature sensor (T2) under the plate sample, incorporated in the tribometer, and (iii) two distinctive infrared based heat reflection measuring devices (T3 and T4), pointed at the sliding contact.

Normal loads and sliding velocities of 15 up to $50 \mathrm{~N}$ and 0.3 up to $0.9 \mathrm{~m} / \mathrm{s}$ respectively were applied. The stroke length of the oscillating motion was $15 \mathrm{~mm}$. Before each test, the specimens were cleaned ultrasonically with acetone. The wear scars were analysed by scanning electron microscopy (SEM, XL-30 FEG, FEI, The Netherlands), equipped with an energy dispersion X-ray spectroscopy system (EDS).

\section{Results and discussion}

Frictional heating. The applied normal force $\left(\mathrm{F}_{\mathrm{N}}\right)$ and the concomitant tangential friction force $\left(\mathrm{F}_{\mathrm{T}}\right)$ were recorded continuously, using a load-cell and a piezoelectric transducer respectively. The $\mathrm{F}_{\mathrm{T}} / \mathrm{F}_{\mathrm{N}}$ forces ratio is defined as the friction coefficient $(\mu)$. At the same time, temperature curves, caused by frictional heating of the sliding $\mathrm{WC} 6 \mathrm{Co}(\mathrm{Cr} / \mathrm{V})$ flat/ $\mathrm{WC} 6 \mathrm{Co}(\mathrm{Cr} / \mathrm{V})$ pin contact, were acquired as function of sliding distance by different measuring techniques, Fig. 1.
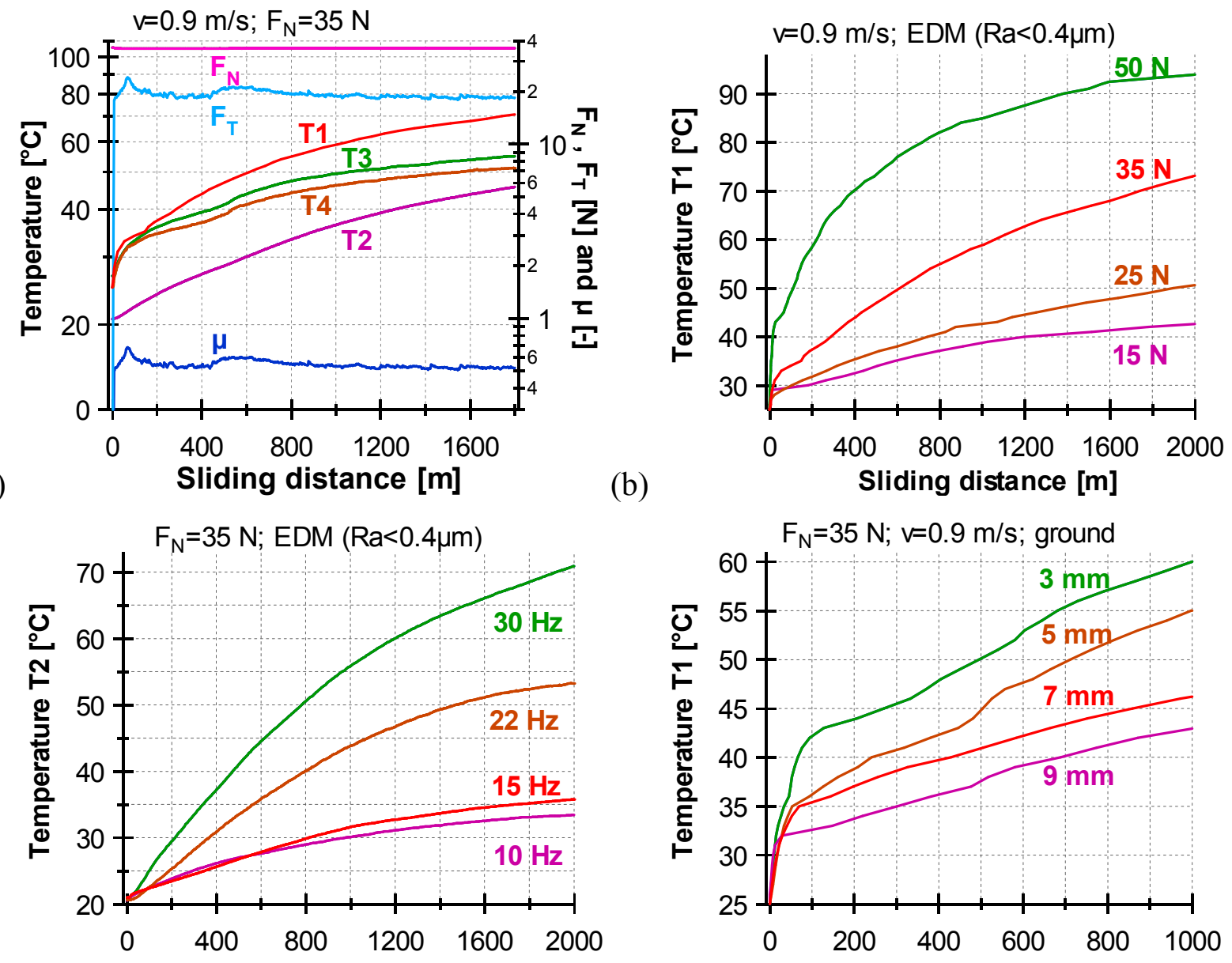

(c)

Sliding distance $[\mathrm{m}]$

(b)

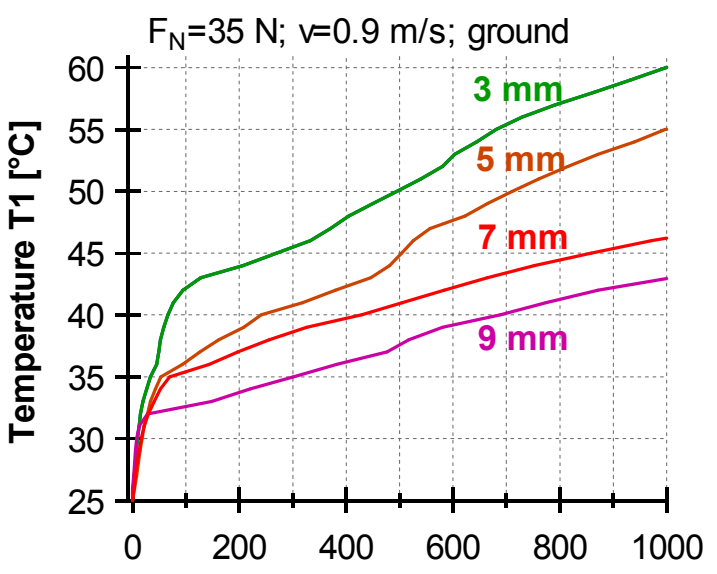

(d)

Sliding distance $[\mathrm{m}]$

Fig. 1: (a) real-time friction and temperature, (b) effect of contact load, (c) effect of sliding speed, (d) effect of thermocouple distance to sliding contact, for $\mathrm{WC6} C o(\mathrm{Cr} / \mathrm{V}) / \mathrm{WC6} \mathrm{Co}(\mathrm{Cr} / \mathrm{V})$ pin on plate tribocouples 
Each curve is an average of at least two wear experiments performed under identical conditions, with a standard deviation of less than $10 \%$ between different samples of the same material. The error bars indicating the extent of the variations are excluded to make the figure better readable. Friction force and friction coefficient are noticed to increase abruptly during initial sliding contact and, after a running-in stage, reach a steady state regime, in which the variations become marginal, Fig. 1(a). The fluctuations in the friction curve are also found in the temperature plots. The T1- and T2-curve seem to vary similarly as function of the sliding distance, except for the initial stage. The highest temperatures are predicted by T1, the lowest values occur for T2, whereas the T3- and T4values appear somewhere in-between.

Grossly, it can be stated that temperature varies exponentially as function of sliding wear path. For example, the following correlation is obtained for $50 \mathrm{~N}$ curve in Fig. 1(b):

$$
\mathrm{T}(\mathrm{s})=25.4160 \cdot \mathrm{s}^{0.1659}\left(\mathrm{R}^{2}=0.9708\right) \text {. }
$$

The R-square value indicates that the equation matches the experimental results quite well. Furthermore, rising contact load and sliding velocity are noticed to increase the effect of frictional heating quite pronounced, as illustrated in Fig. 1(b,c). The distance $(\delta)$ between the thermocouple and the sliding wear contact turns out to affect the T1-temperature as well. The curves in Fig. 1(d) allow to perform a curve fitting procedure in order to predict the frictional heating nearby the sliding contact surface. For instance, a wear path length of $400 \mathrm{~m}$ corresponds with a temperature rise $\Delta \mathrm{T}$ of $11,13,16$ and $21{ }^{\circ} \mathrm{C}$ for distances $\delta$ of $9,7,5$ and $3 \mathrm{~mm}$ respectively, resulting in following empirical equation:

$$
\Delta \mathrm{T}(\delta)=40.4210 \cdot \delta^{-0.5864}\left(\mathrm{R}^{2}=0.9974\right) .
$$

Based on tribothermal analysis [6], with the assumption that convection is neglectible and that the frictional heating is conducted away from the sliding contact into the pin and its holder and into the plate as well, M.F. Ashby et al. derived a model for calculation of "bulk" heating of the specimens, i.e. the surface temperature of the pin in the region near the sliding interface, $\mathrm{T}_{\mathrm{S}}$ :

$$
T_{S}=T_{\text {test }}+\frac{\mu F_{N} V}{2 \sqrt{\pi} \cdot K \cdot r_{0}} \cdot\left[\frac{1+\pi}{2 \cdot \operatorname{tg}^{-1} \sqrt{\frac{2 \pi a}{V \cdot r_{0}}}}\right]^{-1} \text {. }
$$

where $\mu$ is the friction coefficient, $F_{N}$ is the normal load force, $K$ is the thermal conductivity, $V$ is the sliding velocity, $T_{\text {test }}$ is the ambient test temperature, $r_{0}$ is the wear scar radius (contact radius), and $a$ represents the thermal diffusivity of the material.

Wear surface analysis. Wear track analysis by scanning electron microscopy revealed that the wear process of the WC-Co cemented carbides is mainly controlled by abrasion, grain cracking, grain fracture, binder removal and grain pull out [5]. These observations are confirmed by Fig. 2, in wich cross-sectioned views of worn surfaces, resulting from reciprocative dry sliding tests on ground $\mathrm{WC} 12 \mathrm{Co}(\mathrm{V})$ cemented carbides against $\mathrm{WC} 6 \mathrm{Co}(\mathrm{Cr} / \mathrm{V})$ grade pins with a $50 \mathrm{~N}$ contact load and distinctive sliding velocities, are presented. Furthermore, the wear surface originating from the "high speed" sliding appears to exhibit traces of binder modification within a thin subsurface zone, Fig. 2(b), contrary to the "low speed" sliding wear surface, Fig. 2(a). Indeed, increasing velocity causes the adhesive effect of welding between pin and plate to be more pronounced, resulting in more frictional heating and higher bulk temperatures, and thus, increasing the probability of affecting the metallic binder phase [7]. 
(a)

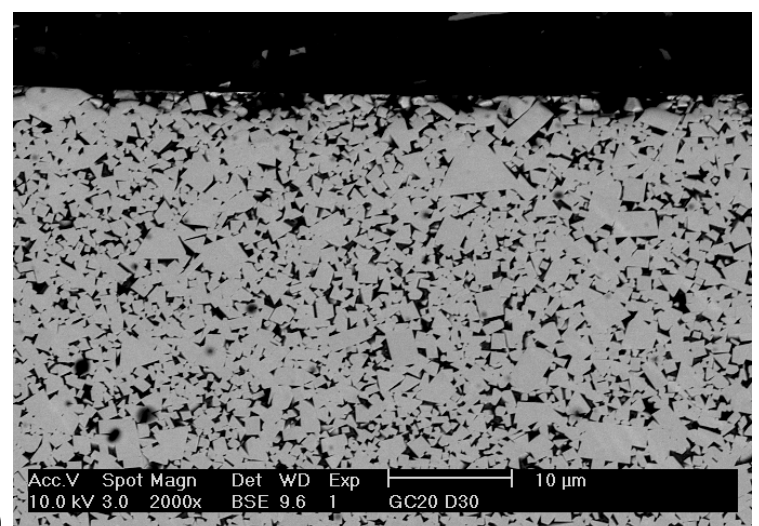

(b)

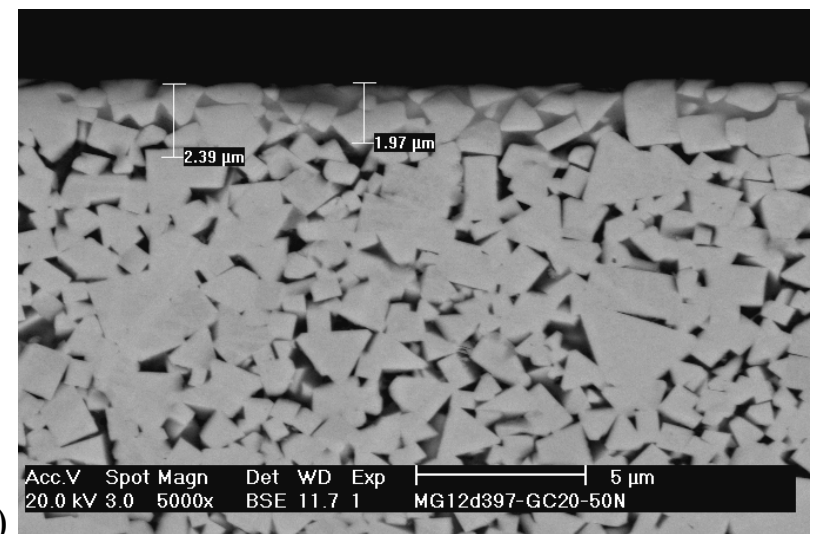

Fig. 2: BSE micrographs in the wear (sub)surface of ground $\mathrm{WC12Co}(\mathrm{V})$ after sliding under a $50 \mathrm{~N}$ contact load at (a) $0.45 \mathrm{~m} / \mathrm{s}$ and (b) $0.9 \mathrm{~m} / \mathrm{s}$

\section{Conclusions}

Systematic reciprocative dry sliding experiments on ground and wire-EDM'ed WC-Co cemented carbides against WC-Co pins, imposing various testing parameters, revealed the occurrence of several wear mechanisms. The impact of frictional heating was assessed using different techniques. The bulk temperature was found to rise exponentially as function of sliding distance and was demonstrated to be dependent on the coefficient of friction and the distance from the sliding wear contact. Rising contact load and sliding velocity increase the effect of frictional heating considerably in terms of temperature rise, and thus, also increase the probability of surface binder phase modification.

\section{Acknowledgements}

This research was co-financed by the Flemish Institute for the promotion of Innovation by Science and Technology in industry (IWT). The authors gratefully recognize the support and scientific contributions from the Ghent University (UGent) and the Catholic Leuven University (K.U.Leuven). Special appreciation goes to CERATIZIT for supplying the cemented carbide grades.

\section{References}

[1] P.S. Sreejith, B.K.A. Ngoi, Dry machining: machining of the future. J. Mater. Process. Technol. 101 (2000), 287-291

[2] F. Klocke, G. Eisenblatter, Dry cutting, Ann. CIRP Vol. 46(2) (1997), 519-526

[3] Acchar W., Gomes U., Kayser W., Goring J., Strength degradation of a tungsten carbide-cobalt composite at elevated temperatures, Mater. Charact. 17 (1999), 55-68

[4] K. Bonny, P. De Baets, B. Lauwers, J. Vleugels, O. Van Der Biest, "Influence of electro-discharge machining, microstructural and mechanical properties on wear of hardmetals", Plansee 16th Int. Sem., Vol. 2 (2005), 863-877

[5] K. Bonny, P. De Baets, B. Lauwers, W. Liu, J. Vleugels, S. Salehi, O. Van Der Biest, Reciprocative sliding wear behavior of WC-Co Cemented Carbides, submitted to Int. J. Refr. Met. \& Hard Mater.

[6] Ashby M.F., Abulawi J., Kong H.S., Temperature maps for Frictional Heating in Dry Sliding, Tribology Transactions (1991), 577-587

[7] V. Voitovich, V. Sverdel, R. Voitovich, E. Golovko, Oxidation of WC-Co, WC-Ni and WC-Co-Ni hardmetals in the temperature range $500-800{ }^{\circ} \mathrm{C}$, Int. J. Refract. Met. Hard Mater. Vol. 14 (1996), 289-295 